\title{
Study of the Level of Polycyclic Aromatc Hydrocarbons (PAHs) in Some Locally Smoked Fish Species
}

\author{
*Jimah, A. Ogiedu, T. A. \\ Department of Food Technology, Auchi Polytechnic Auchi
}

\begin{abstract}
Polycyclic aromatic hydrocarbons (PAHs) are carcinogenic pollutants which get into foods during processing. In spite of this, only a few studies have been carried out on Nigerian delicacies. This study was used to determine the level of PAHs in some smoked fish species namely: clarias gariepenus (catfish), scomber scombrus (atlantic mackerel) and clupea harengus (herring fish). The fish species were smoked with a local open-fire fish smoking drum and PAHs were determined using the Gas Chromatography (GC) coupled with flame ionization detector (FID). The levels of PAHs were evaluated on the three species of fish. The total values of PAHs have shown that the smoked clarias gariepenus (catfish), scomber scombrus (mackerel fish) and clupea harengus (herring fish) have $80.01 \mu \mathrm{g} / \mathrm{g}, 69.94 \mu \mathrm{g} / \mathrm{g}$ and $154.08 \mu \mathrm{g} / \mathrm{g}$ respectively. Higher values were found in benzo(a)pyrene and lower values found in naphthalene. For benzo(a)pyrene, the values were $9.20 \mu \mathrm{g} / \mathrm{g}, 2.90 \mu \mathrm{g} / \mathrm{g}$ and $40.13 \mu \mathrm{g} / \mathrm{g}$ respectively. For naphthalene, the values were $1.13 \mu \mathrm{g} / \mathrm{g}, 1.11 \mu \mathrm{g} / \mathrm{g}$ and $1.72 \mu \mathrm{g} / \mathrm{g}$ respectively. Benzo(a)pyrene, which is highly carcinogenic was found to have the highest concentration in clupea harengus (herring fish) of about $40.13 \mu \mathrm{g} / \mathrm{g}$ which is above permissible level. As for the other PAHs, they were all detected in various quantities which resulted to the high level of the total PAHs in the samples. From the study, it was revealed that the open-fire fish smoking pose a health risk for human as it is being contaminated. It is therefore recommended that a low polycyclic aromatic hydrocarbons (PAHs) improved fish smoking kiln should be developed.
\end{abstract}

Keywords: Polycyclic aromatic hydrocarbons, smoked fish, Gas chromatography, Benzo(a)pyrene, Carcinogenic

DOI: $10.7176 / \mathrm{CMR} / 13-3-03$

Publication date:October $31^{\text {st }} 2021$

\section{INTRODUCTION}

Polycyclic aromatic hydrocarbons (PAHs) constitute a large class of organic compounds that are composed of two or more fused aromatic rings. They are a class of ubiquitous environmental pollutants which can be generated during the preparation of food (Agerstad and Skog, 2005). They are primarily formed by incomplete combustion or pyrolysis of organic matter and during various industrial processes (Silva et al, 2011). PAHs generally occur in complex mixtures which may consist of hundreds of compounds. Humans are exposed to PAHs by various pathways. While for non-smokers the major route of exposure is consumption of food, for smokers the contribution from smoking may be significant (Agerstad and Skog, 2005). Food can be contaminated from environmental sources, industrial food processing and from certain home cooking practices (EFSA, 2008). On the other hand, PAHs are also found in foods as a result of certain industrial food processing methods such as smoke curing, broiling, roasting and grilling over open fires or charcoal which permits the direct contact between food and combustion products (Silva et al., 2011). In general, PAHs are not present individually but in mixtures. Sixteen PAHs that have been extensively monitored are the compounds included in the United States Environmental Protection Agency (USEPA) list of priority organic pollutants (USEPA, 1994). Of these 16 PAHs, Benzo(a)pyrene $(\mathrm{BaP})$ is probably the most studied and has been described by the International Agency for Research on Cancer (IARC) as probable human carcinogen in 1987 (IARC, 1987). Thus, the determination of $\mathrm{BaP}$ has been widely used in environmental analysis as marker for the entire $\mathrm{PAH}$ content (Otahen, 2021).

Across Africa, various traditional methods are employed to process, preserve and store fish. These include smoking, drying, salting, frying and fermenting and various combinations of these treatments (SFMP, 2016). Smoking is a traditional processing technique used to preserve fish. It also gives colour and a range of tastes appreciated by consumers. It consists of exposing fish to the effects of heat and smoke, both produced by the combustion of biomass (wood, sawdust, coconut husks, etc) (Kamaldeen et al, 2016). The advantages of smoking fish are manifold: it prolongs shelf life, enhances flavour, reduces waste in times of bumper catches and permits storage for the lean season. It increases protein availability to people throughout the year and makes fish easier to pack, transport and market. It is a major source of income for coastal-dwelling communities and traders. In Nigeria, smoking is the most widely-used method for preserving fish and is the most common activity for women in fishing communities. Out of the total of 194,000 metric tons of dry fish produced in Nigeria, about $61 \%$ of it was smoked (Silva et al, 2011). It has been estimated that between 70 and 80 percent of the domestic marine and freshwater fish catch is consumed in smoked form (SFMP, 2016).

The actual levels of PAHs in smoked foods depend on several variables in the smoking process, including 
type of smoke generator, combustion temperature, and degree of smoking (Silva et al, 2011). The composition of the smoke and the conditions of processing affect the sensory quality, shelf life, and wholesomeness of the product. Potential health hazards associated with smoked foods may be caused by carcinogenic components of wood smoke; mainly PAHs, derivatives of PAHs, such as nitro-PAH or oxygenated PAH and to a lesser extent heterocyclic amines (Silva et al, 2011). The smoke for smoking of food develops due to the partial burning of wood, predominantly hardwood, softwood and bagasse. Several researchers have investigated the presence of PAHs in food samples. In 1964, the presence of benzo(a)pyrene (BaP) and other related PAHs were first reported to be present in charcoal broiled beef. PAHs have been detected at different concentrations in liquid fatty matrices e.g. edible oils (Barranco et al., 2004), olive oil (Bogusz et al., 2004) and milk (Kishikawa et al., 2003), liquid non fatty matrices e.g. coffee (García- Falcón et al., 2005) and tea (Lai et al., 2004), solid fatty matrices e.g. smoked meat (Chiu et al., 1997), fish (Pensado et al., 2005; Silva et al., 2011) and infant milk and cereal (Rey-Salgueiro et al., 2009) as well as solid non fatty matrices e.g. fruits and vegetables (Rojo Camargo and Toledo, 2003) and tea leaves (Lin and Zhu, 2004).

The production and consumption of fish in Nigeria has been a major source of animal protein which has competed favourably with meat. Fish has been reported to be a very important delicacy in Nigeria. It has enjoyed wide acceptability in most parts of the country because of its unique taste, flavour and good texture. It is widely distributed, extensively consumed. This study therefore investigated the use of traditional open-fire drum for fish smoking process on three species of fishes: clarias gariepenus (Catfish), scomber scombrus (Atlantic mackerel) and clupea harengus (Herring fish) and to monitor the effects of smoking on the levels of polycyclic aromatic hydrocarbons (PAHs) of these locally consumed fishes in Nigeria.

\section{MATERIALS AND METHODS \\ Collection of Materials}

The fish scomber scombrus (atlantic mackerel) and clupea harengus (herring fish) were purchased from a local cold store at Uchi market, here in Auchi. The clarias gariepenus (catfish) was purchased from a seller in Uchi market, Auchi, Edo state of Nigeria. The firewood used in the generation of heat and smoke were sourced from a local seller while the traditional Open-fire drum for the smoking was at the Department of Food Science and Technology, Auchi Polytechnic Auchi.

\section{Smoking of Fish}

Clean water was used to wash the fish before gutting and they were washed again and drained. The fish were spread in trays and taken for smoking. The firewood was used in this case of traditional open-fire drum called. During the smoking the fish were turned to opposite side from every 30minutes interval for even drying and smoking. The fire was continually being controlled for optimum heating by adding and removing firewood. The smoking was done for about 7-8hours. After the drying processes, the smoked and dried fish were cooled and packaged and samples were taken to the laboratory for PAHs analysis.

\section{Analysis of PAHs}

Extraction: The samples were each pulverized using a manual grinding machine to ensure homogenization. Five grams $(5 \mathrm{~g})$ of the pulverized sample was thoroughly mixed with $10 \mathrm{~g}$ of anhydrous sodium sulphate in a mortar (Amos-Tautua et al, 2013) to absorb moisture. The homogenate was placed into an extraction thimble and covered with a Whatman filter paper $(125 \mathrm{~mm}$ diameter).This was then inserted into a Soxhlet extraction chamber of the Soxhlet extraction unit. Extractions were then carried out with $50 \mathrm{~mL}$ mixture of redistilled nhexane and dichloromethane in the ratio 3:1 for effective recovery. Subsequently, the crude extract was filtered through a layer of anhydrous sodium sulphate. The obtained filtrate was evaporated to near dryness.

Clean up: The clean-up of the extract was carried out using activated silica gel and anhydrous $\mathrm{Na}_{2} \mathrm{SO}$. The silica gel column was prepared by loading an activated silica gel $(12 \mathrm{~g})$ onto a chromatographic column $(\mathrm{id}=1 \mathrm{~cm})$. About $1 \mathrm{~g}$ of anhydrous $\mathrm{Na}_{2} \mathrm{SO}_{4}$ was added to the top of the silica gel in the column. After conditioning the columns with $20 \mathrm{~mL}$ hexane the sample was applied and eluted with $200 \mathrm{ml}$ of mixture of Dichloromethane : Hexane (3:1). The eluate was collected into an evaporating flask and rotary evaporated to near dryness. The dry eluate was then dissolved in $1 \mathrm{~mL} n$-hexane for Gas Chromatographic analysis (Amos-Tautua et al, 2013).

Instrumental analysis: The polycyclic aromatic hydrocarbon analysis was carried out using gas chromatograph system. The system consisted of a Hewlett Packard Model 5890 gas chromatography (GC) equipped with a flame ionization detector (FID) and a data processor (Hewlett Packard, Wilmington, DE, USA). The column used was HP-1932530, a non-polar, fused-silica capillary column $(30 \mathrm{~m}$ length $\times 25 \mu \mathrm{m}$ inner diameter $\times 0.25 \mu \mathrm{m}$ film thickness). The oven temperature was set initially at $60^{\circ} \mathrm{C}(5 \mathrm{~min}$ hold $)$, increased to $250^{\circ} \mathrm{C}$ at $15^{\circ} \mathrm{C} / \mathrm{min}$. (4min hold) and a final temperature of $320^{\circ} \mathrm{C}$ at $10^{\circ} \mathrm{C} / \mathrm{min}(4 \mathrm{~min}$ hold). Nitrogen gas was used as the carrier gas at a flow rate of $1 \mathrm{~mL} / \mathrm{min}$ at a pressure of $30 \mathrm{psi}$. The injector temperature was set at $250^{\circ} \mathrm{C}$, injection volume was $1 \mathrm{~mL}$ and the detector temperature was set at $320^{\circ} \mathrm{C}$. Verification of peaks was carried out based on retention 
times compared to those of external PAHs standards (Amos-Tautua et al, 2013).

\section{RESULTS}

Table 1: Concentration of PAHs $(\mu \mathrm{g} / \mathrm{g})$ in some locally smoked fish species clarias gariepenus, scomber scombrus and clupea harengus

\begin{tabular}{llll}
\hline & \multicolumn{2}{c}{ Samples } & \\
\cline { 2 - 4 } Parameters & Clarias gariepenus & Scomber scombrus & Clupea harengus \\
\hline Naphthalene & 1.1344 & 1.1120 & 1.7239 \\
Acenaphthylene & 4.2963 & 4.2560 & 25.5991 \\
Acenaphthene & 2.1183 & 6.8387 & 0.9505 \\
Fluorene & 0.3372 & 4.8437 & 3.0208 \\
Phenanthrene & 1.2923 & 1.6390 & 1.4623 \\
Anthracene & 1.2094 & 12.9366 & 31.7157 \\
Fluoranthene & 22.0752 & 3.7258 & 6.8926 \\
Pyrene & 12.3981 & 7.3887 & 16.7740 \\
Chrysene & 4.4259 & 5.7816 & 2.6208 \\
Benzo(a)anthracene & 6.9393 & 1.4210 & 6.2473 \\
Benzo(b)fluoranthene & 2.4837 & 6.6279 & 6.7336 \\
Benzo(k)fluoranthene & 5.9991 & 1.1861 & 1.4464 \\
Benzo(a)pyrene & 9.2002 & 2.8987 & 40.1324 \\
Indeno(1,2,3-cd)pyrene & 1.7632 & 5.0391 & 4.5653 \\
Dibenzo(a,h)anthracene & 2.0086 & 1.8127 & 1.4464 \\
Benzo(g,h,i)perylene & 2.3285 & 2.4324 & $2.7323-$ \\
TOTAL PAHs ( $\boldsymbol{\mu g} / \mathbf{g})$ & $\mathbf{8 0 . 0 0 9 5}$ & $\mathbf{6 9 . 9 4 0 2}$ & $\mathbf{1 5 4 . 0 8 1 6}$ \\
\end{tabular}

Figure 1 showed Chromatograms of the concentration of PAHs $(\mu \mathrm{g} / \mathrm{g})$ in some locally smoked fish species clarias gariepenus, scomber scombrus and clupea harengus respectively

\section{DISCUSSION}

PAHs were analysed and the results are shown in table 4.1. The sixteen PAHs were detected and the total PAHs showed that smoked clupea harengus (herring fish) has the highest level of total PAHs of $154.08 \mu \mathrm{g} / \mathrm{g}$, followed by smoked clarias gariepenus (catfish) with $80.01 \mu \mathrm{g} / \mathrm{g}$ and the least contaminated was smoked scomber scombrus (Atlantic mackerel) fish with $69.94 \mu \mathrm{g} / \mathrm{g}$ respectively. The result also showed that Benzo(a)pyrene, a bio-indicator, which is very carcinogenic even at low concentration was highest in smoked herring fish with $40.13 \mu \mathrm{g} / \mathrm{g}$. This is because the fish has a lot of fats/oils that dripped on open flame forming those PAH molecules. Benzo(a)pyrene is the most studied carcinogenic polycyclic aromatic hydrocarbon and one of the most potent and it is often used as a toxicological prototype or surrogate for all carcinogenic PAHs (Collins, et al) The EU has established a maximum permissible level of $\mathrm{BaP}$ of $5 \mu \mathrm{g} / \mathrm{kg}$. From the results in table 4.1 , the herring fish and catfish were highly contaminated.

Various fish have different ways of absorbing PAHs. However, individual concentrations of the carcinogenic PAHs ranged from highly detectable in the fish samples were anthracene in smoked herring fish with $31.72 \mu \mathrm{g} / \mathrm{g}$ and acenaphthalene in smoked herring fish with $25.60 \mu \mathrm{g} / \mathrm{g}$ to the low level fluorene in catfish with $0.34 \mu \mathrm{g} / \mathrm{g}$. There are other components such as naphthalene in smoked catfish with $1.13 \mu \mathrm{g} / \mathrm{g}$, followed by the Atlantic mackerel with $1.11 \mu \mathrm{g} / \mathrm{g}$ and smoked herring fish with $1.72 \mu \mathrm{g} / \mathrm{g}$ respectively and phenanthrene ranging from $1.29 \mu \mathrm{g} / \mathrm{g}, 1.64 \mu \mathrm{g} / \mathrm{g}$ and $1.46 \mu \mathrm{g} / \mathrm{g}$ in the fish samples respectively. These are detected in low quantity and they are also of lower molecular weight PAHs which not be too carcinogenic as that of BaP. The maximum permissible level weight for smoked meat and meat products, although a legal limit of $1 \mu \mathrm{g} / \mathrm{kg} \mathrm{had}$ previously been adopted by some European countries (Lorenzo et al, 2011).

The amount of PAHs formed during the processing of fish depends mostly on the conditions of smoking. In this traditional smoking, smoke is generated at the bottom of an oven and the fish is placed directly over the smoking wood. In these conditions, PAHs are mainly produced by the following:

- incomplete combustion of wood: generation of wood smoke during curing is a typical example of incomplete combustion, and above $400^{\circ} \mathrm{C}$ PAHs are generated and released into the various smoked products

- $\quad$ oil pyrolysis: the formation of PAHs is known to occur through pyrolysis of oil at temperatures above $200^{\circ} \mathrm{C}$ and it is highly stimulated at temperatures over $700^{\circ} \mathrm{C}$. 
- When the fish is placed over the wood, oil drops in direct contact with the flame, generating PAHs that become deposited back on the fish (SFMP, 2016).

- In most cases cooking and smoking phases are performed in the same chamber at the same time, therefore exposing the fish to PAHs over a long time, especially for the hot smoking process.

- Critically, since little to nothing is done to prevent oil from dropping directly in the fire or immediately next to it, additional amounts of PAHs are generated by the fire and these pass into the gas stream (Kamaldeen et al, 2016).

- The main issues with the traditional stoves is that poor control of the fire power resulting in high temperatures well above optimum (Kamaldeen et al, 2016).

All mentioned authors attribute the highest PAH generation during grilling or barbecue through pyrolysis during charbroiling of fish products and either deposition and penetration of smoke components into foods and they found a link between fat foods and PAH levels. Biological membranes are mostly composed of lipids (oils); majority of organic pollutants are lipophilic. It has been suggested that the larger the lipid content of the biological membrane, the higher is the rate of uptake of pollutants (Silva et al., 2011). The hypothesis is that melted fat from the heated fish drips onto the hot flame and is pyrolyzed, giving rise to PAHs generation, which are then deposited on the fish surface as the smoke rises. Their findings were consistent with the findings of this study.

\section{CONCLUSION}

From the study, it was revealed that the smoked fish samples represent a health risk for human, since benzo(a)pyrene is considered as a marker of carcinogenic. It should be stated here that the herring fish and catfish were highly contaminated because of the high level of benzo(a)pyrene. Also, it should also be stated that the mackerel is also contaminated in total PAHs using this traditional open fire drum smoking. Considering this carcinogenic potential of these PAHs, it is recommended that an improved smoking kiln should be developed.

\section{ACKNOWLEDGEMENT}

The authors are thankful to TETfund for providing this Institution Based Research (IBR) grant to facilitating this research. This indeed has given us the opportunity to contribute our quota to the nation building in term of food production and development. Thank you so much.

\section{DEDICATION}

This work is dedicated to the memory of my Co-researcher, the late Mr Ogiedu, T. A. who had passed on during the period of this research. May his soul rest in peace - Amen

\section{REFERENCES}

Agerstad, M.J. and Skog, K. (2005). Review genotoxicity of heat-processed foods. Mutation Research, 574:156-172.

Amos-Tantua, B. M. W., Inengite, A. K., Abasi, C. Y. and Anirize, G. C. (2013). Evaluation of Polycyclic Aromatic Hydrocarbons and some Heavy Metals in Roasted Food Snacks in Amassoma, Niger-Delta, Nigeria. African Journal of Environmental science and Technology 7(10) 961 - 966

Barranco, A., Alonso-Salces, R.M., Corta, E., Berrueta, L.A., Gallo, B., Vicente, F. and Sarobe, M. (2004). Comparison of donor-acceptor and alumina columns for the clean up of polycyclic aromatic hydrocarbons from edible oils. Food Chemistry, 86:465-474.

Bogusz, M. J., El Hajj, S. A., Ehaideb, Z., Hassan, H.and Al-Tufail, M. 2004. Rapid determination of benzo(a)pyrene in olive oil samples with solid-phase extraction and low-pressure, wide-bore gas chromatography-mass spectrometry and fast liquid chromatography with fluorescence detection. Journal of Chromatography, 1026:1 - 7

Chiu, C.P., Lin, Y.S. and Chen, B. H. (1997). Comparison of GC-MS and HPLC for overcoming matrix interferences in the analysis of PAHs in smoked food. Chromatographia, 44:497 - 504.

Collins, J. F., Brown, J. P., Dawson, S. V. and Marty M. A. (1991). Risk Assessment for Benzo(a)pyrene. Regulatory Toxicology and Pharmacology. 13: 170 - 184

EFSA (2008) Polycyclic Aromatic Hydrocarbon in food, European Food Safety Authority EFSA journal 724, 1114

Fetzer, J. C. (2000). "The Chemistry and Analysis of the Large Polycyclic Aromatic Hydrocarbons". Polycyclic Aromatic Compounds. Wiley, New York. 27(2):143 162.

García-Falcón, M. S., Cancho-Grande, B. and Simal-Gándara, J. (2005). Minimal clean-up and rapid determination of polycyclic aromatic hydrocarbons in instant coffee. Food Chemistry, 90:643 - 647.

IARC. (1987). Overall evaluation of carcinogenicity: IARC Monographs on the Evaluation of Carcinogenic Risks to Humans, Suppl. 7, 1-42, International Agency for Research on Cancer, Lyon. 
Kamaldeen, O. S., Isiaka, A. A., Arowora, K. A., \& Awagu, E. F. (2016). Development of Improved Fish Smoking Kiln. International Journal of Engineering Science and Computing. (7) 1925 -1932)

Kishikawa, N., Wada, M., Kuroda, N. Akiyama, S. and Nakashima, K. (2003). Determination of polycyclic aromatic hydrocarbons in milk. Journal of Emerging Trends in Engineering and Applied Sciences $3(5): 857-862$

Lin, D. and Zhu, L. (2004). Polycyclic Aromatic Hydrocarbons: Pollution and Source. Analysis of a Black Tea. Journal of Agricultural and Food Chemistry, 52: 826-8271.

Lai, J. P., Niessner, R. and Knopp, D. (2004). Benzo[a]pyrene imprinted polymers: synthesis, characterization and SPE application in water and coffee samples. Analytica Chimica Acta, 522:137 -144.

Larsson, B. and Sahlberg, G. (1982). Polycyclic aromatic hydrocarbons in lettuce. Influence of a highway and an aluminium smelter: Physical and biological Chemistry. Colombus, Ohio, Battelle Press. 417- 426.

Lorenzo, J. M., Purrinos, L., Bermuddez, R., Cobas, N., Figueirodo, M. and Garcia M. C. (2011) Polycyclic Aromatic Hydrocarbons (PAHs) in two Spanish traditional Smoked sausage varieties. Meat Science. 89: $105-109$

Otahen, S. O. (2021). Study of the Level of Polycyclic Aromatic Hydrocarbons in Smoked Fish. A Project Work of Food Technology Department, Auchi Polytechnic Auchii. Unpublished pp 26, 31 - 35

Pensado, L., Casais, M.C., Mejuto, M.C. and Cela, R.(2005). Application of matrix solid phase dispersion in the analysis of priority polycyclic aromatic hydrocarbons in fish samples. Journal of Chromatography. 1077:103 -109.

Rey-Salgueiro, L., Martínez-Carballo, E., García- Falcón, M .S, González-Barreiro, C. and Simal- Gándara, J. (2009). Occurrence of polycyclic aromatic hydrocarbons and their hydroxylated metabolites in infant foods. Food Chemistry, 115: 814 - 819.

Rojo Camargo, M.C. and Toledo, M.C.F. 2003.Polycyclic aromatic hydrocarbons in Brazilian vegetables and fruits. Food Control, 14: 49 - 53.

SFMP (2016). Low PAHs Improved Fish Smoking Stove Design Development Report. Sustainable Fisheries Management Project, USAID/GHANA. P $7-8$ and $15-20$

Silva, B. O., Adetunde, O. T., Oluseyi, T. O., Olayinka, K. O. \& Alo, B. I. (2011). Effects of Methods of Smoking on the Levels of PAHs in Some Locally Consumed Fishes in Nigeria. Africa Journal of Food Sciences 5(7): 384 - 391

USEPA (1994). (United States Environmental Protection Agency), Appendix A Part 423 http://www.epa.gov/waterscience/methods/pollutants. html 
CHROMATOGRAM FOR PAH ANALYSIS

DIL/OTA/F/A/ARO

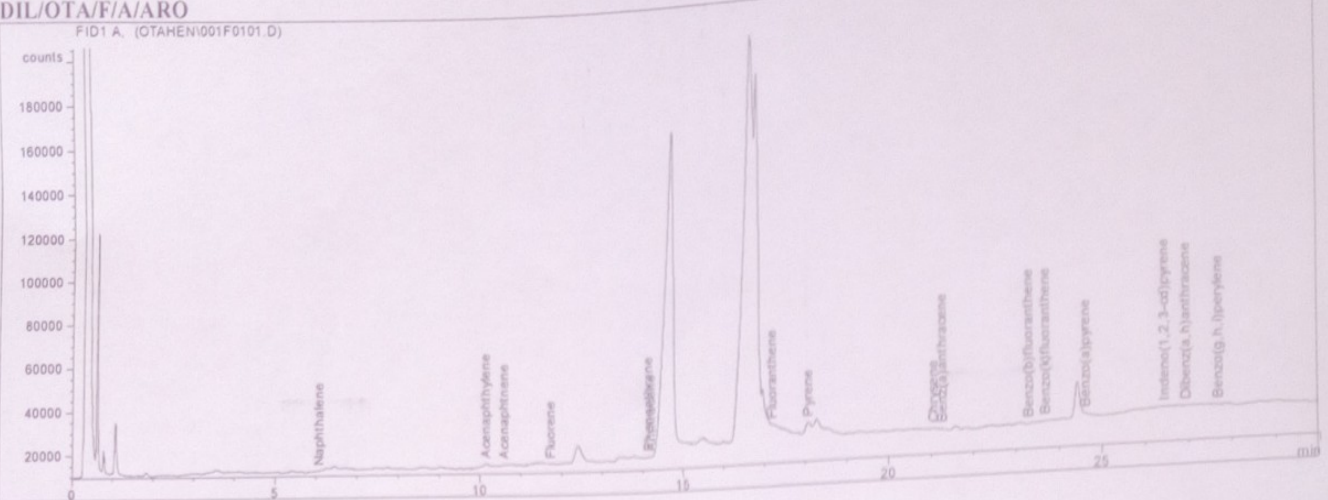

DIL/OTA/F/B/ARO
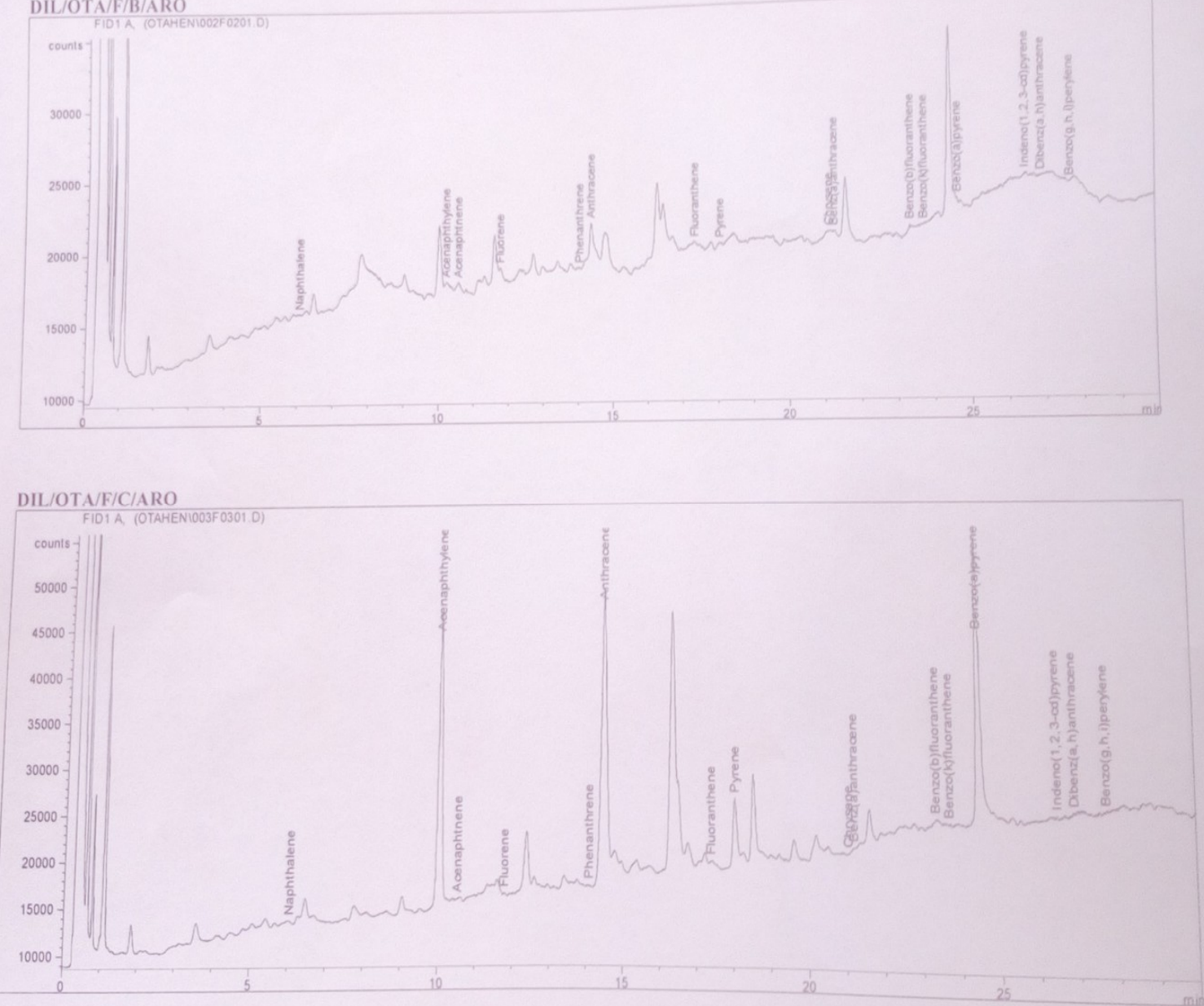

Figure 1: Chromatograms of the concentration of PAHs $(\mu \mathrm{g} / \mathrm{g})$ in some locally smoked fish species clarias gariepenus, scomber scombrus and clupea harengus respectively 